\title{
Total Clearance Predicted by Fraction Dose Normalized by Body Mass Index
}

National Cancer Institute

\section{Source}

National Cancer Institute. Total Clearance Predicted by Fraction Dose Normalized by

Body Mass Index. NCI Thesaurus. Code C92417.

The predicted total body clearance for extravascular administration based on the fraction of dose absorbed and divided by the body mass index. 